\title{
Transcription-dependent recombination induced by triple-helix formation
}

\author{
Yoshinori Kohwi ${ }^{1}$ and Yurij Panchenko \\ La Jolla Cancer Research Foundation, La Jolla, California 92037 USA
}

\begin{abstract}
The homologous recombination between direct repeat sequences separated by either 200 or 1000 bp was induced by active transcription of the downstream gene when poly(dG)-poly(dC) sequences exist between the two direct repeats. This dG tract-mediated and transcription-induced recombination was RecA independent, and the frequency of recombination was dependent on both the length and the orientation of the poly(dG)-poly(dC) sequences relative to the gene. An intramolecular dG.dG.dC triplex formation was detected in Escherichia coli cells in a length-dependent manner when the transcription of the downstream gene was activated. We suggest that the negative superhelical strain generated by active transcription of the downstream gene induces poly(dG)-poly(dC) sequences to adopt a triple-helix structure in vivo and that this structure brings two remote sequences together to stimulate homologous recombination.
\end{abstract}

[Key Words: recombination; transcription; negative supercoiling; DNA structure; triple helix]

Received March 17, 1993; revised version accepted June 29, 1993.

The factors that influence the degree of supercoiling of a DNA inside a bacterium include transcription, diffusional pathways, gyrase-catalyzed negative supercoiling, and DNA topoisomerase I-catalyzed relaxation of negatively supercoiled DNA (Liu and Wang 1987; Wu et al. 1988). It was first proposed by Liu and Wang (1987) that active transcription may generate a localized positive supercoiled domain and a negative supercoiled domain in front of and behind a transcribing RNA polymerase, respectively. This is based on the concept that the DNA being transcribed may turn around its helical axis instead of the elongating RNA polymerase molecule rotating around the DNA. This twin-supercoiled-domain model has now been supported by considerable evidence from in vitro and in vivo studies (Brill and Sternglanz 1988; Giaever and Wang 1988; Tsao et al. 1989). Because bacterial gyrase and topoisomerase I act differently on positively and negatively supercoiled DNA, in vivo studies for bacteria and yeast have made use of topoisomerase mutants in testing the twin-supercoiled-domain model (Brill and Sternglanz 1988; Giaever and Wang 1988).

Certain DNA sequences adopt non-B DNA structures when subjected to negative superhelical strain. These sequences could be used to probe local superhelical strain inside cells. Previously, we placed one of these sequences, a poly $(\mathrm{dG})-$ poly $(\mathrm{dC})$ sequence $5^{\prime}$ of a reporter gene and examined its effects on transcription in mammalian cells. If supercoiled strain was in fact generated by the process of transcription, this sequence would readily adopt an intramolecular dG.dG.dC triplex struc-

${ }^{1}$ Corresponding author. ture and might exert effects on the level of transcription. Our results suggest that this sequence augments transcriptional activity of the gene when it is in the doublestranded form but not when it is forming a triplex (Kohwi and Kohwi-Shigematsu 1991). In Escherichia coli cells, an intramolecular dG.dG.dC triplex formation was directly demonstrated by chemical probing. This triplex formation was detected in chloramphenicol-treated cells within which there was a higher degree of supercoiling (Kohwi et al. 1992).

Non-B-form DNA structure that would be stabilized by local supercoiling generated by the process of active transcription may have significant effects not only on transcription but also on recombination. Recent work in the site-specific recombination of $\lambda$ phage within the $E$. coli system shows that bending of the phage attachment site, attP, induced by integration host factor (IHF) and superhelical strain exerted on this DNA, contribute to the formation of the active nucleoprotein assembly unit, the intasome (for review, see Landy 1989; Nash 1990). DNA sequences that have the potential to bend can successfully substitute for the attP site and facilitate sitespecific recombination (Goodman and Nash 1989). We decided to test whether non-B DNA structure that would be stabilized by the process of transcription has a significant effect on homologous recombination in an E. coli system.

In the study of homologous recombination, much attention has been given to the steps of DNA strand pairing and the exchange of homologous sequences in which RecA protein plays a central role (for review, see Radding 1988; Smith 1988; Kowalczykowski 1991). It still remains uncertain, however, as to how two homologous 
sequences find each other in the first place to stimulate recombination. In searching for a clue to answer this question, it is of interest that there is considerable evidence for stimulation of recombination by transcription. Correlation between recombination and transcription has been well-documented in the yeast system. A DNA segment containing an RNA polymerase I promoter, HOT1, stimulates recombination of an adjacent gene by polymerase I transcription initiating in the inserted rDNA and proceeding through the adjacent sequence (Voelkel-Meiman et al. 1987). Also in yeast, RNA polymerase II-dependent transcription stimulates direct repeat recombination leading to loss of a plasmid integrated at the GAL10 locus (Thomas and Rothstein 1989 $\mathrm{a}, \mathrm{b})$. In the prokaryotic system, there is also a report suggesting that transcription stimulates recombination (Dul and Drexler 1988). In higher eukaryotes, correlation between transcription and recombination has been suggested on the basis of the fact that transcription of the immunoglobulin variable $(V)$ region genes occurs at a time when the cells are undergoing a B cell-specific $V_{\mathrm{H}^{-}}$ $D /_{\mathrm{H}}$ recombination event (Blackwell et al. 1986; Yancopoulos et al. 1986). It is not certain how transcription stimulates recombination, but it is possible that transcriptionally active chromatin structures make the templates more accessible to both RNA polymerases and recombinases. Alternatively, one could imagine that local supercoiling generated by the process of active transcription induces formation of altered DNA structures and that this subsequently contributes to stimulation of recombination.

In this study we employed poly $(\mathrm{dG})-$ poly $(\mathrm{dC})$ sequences as model sequences to examine the potential role of non-B DNA structures in homologous recombination. Here, we show that the process of active transcription of a downstream gene stabilizes the formation of an intramolecular dG.dG.dC triplex and promotes the homologous recombination between direct repeats in a RecA-independent manner.

\section{Results}

\section{Transcription-dependent recombination assay system}

To examine recombination events under negative superhelical strain induced by transcriptional activation, we employed a strong, isopropyl- $\beta$-D-thiogalactopyranoside (IPTG)-inducible bacterial promoter, the tac promoter (Ptac), (Fig. 1). The pGEX-2T vector (Pharmacia) has one copy of the lac promoter (Plac), which is IPTG inducible but a weaker promoter, in addition to the Ptac promoter. To this vector, one additional copy of the lac promoter (Plac) was introduced upstream of the Ptac promoter. Both Ptac and Plac share homologous sequences that differ only by 2 bases at positions -8 and -9 from the transcriptional start site $(+1)$, sharing the rest of the 53base sequences (see Fig. $3 \mathrm{~A}$, below). In the final construct, there are a total of three homologous, directly repeated sequences as potential sites for recombination. These homologous sequences found in Plac and Ptac pro-

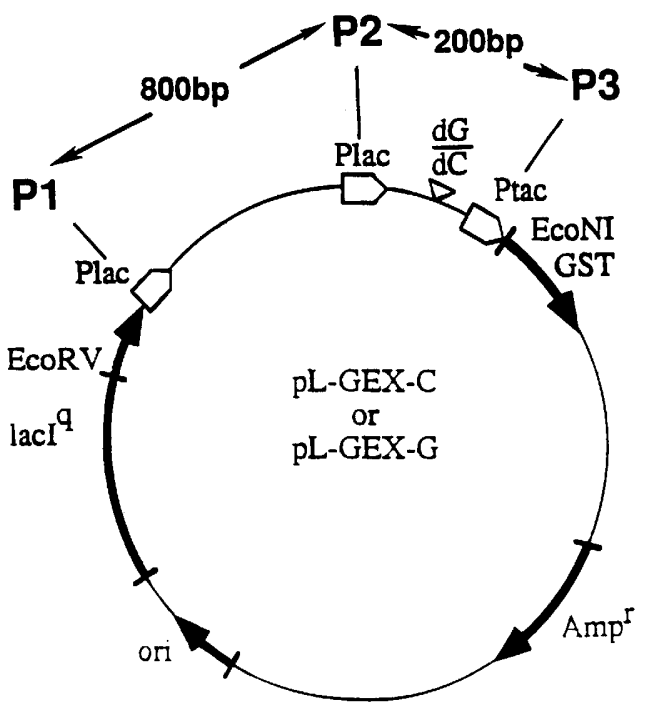

Figure 1. Construction of plasmids for transcription-driven recombination assay. The plasmid pL-GEX was constructed from pGEX-2T (Pharmacia) by introducing a PvuII-EcoRV fragment of the lac promoter (Plac) of Bluescript (Stratagene) as the second Plac at the SspI site of pGEX-2T. The resulting plasmid pL-GEX consists of two Plac and one Ptac promoters in the same direction. EcoRI-BamHI fragments containing various lengths of poly $(\mathrm{dG})-$ poly $(\mathrm{dC})$ sequences from $\mathrm{pCAT}(\mathrm{C} / \mathrm{G})_{n}$ were introduced at the XhoI site of pL-GEX, almost at the center of $170 \mathrm{bp}$ between the second Plac and the Ptac. The poly(dG) sequence on the top strand (the coding strand of the GST gene) was named as pL-GEX-G. The poly(dC) sequence on the top strand was named as pL-GEX-C. P1, P2, and P3 represent the identical sequences of $5^{\prime}$-lac promoter $\left(5^{\prime} \mathrm{Plac}\right), 3^{\prime}$-lac promoter $\left(3^{\prime} \mathrm{Plac}\right)$ and tac promoter (Ptac), respectively (see Fig. 3). The map is not drawn to scale.

moters are designated as $\mathrm{P} 1$ (in $5^{\prime}$-Plac), $\mathrm{P} 2$ (in $3^{\prime}$-Plac), and P3 (in Ptac) as shown in Figure 1. P1 and P2 are 800 bp apart, and P2 and P3 are 200 bp apart. In addition, varying lengths of poly $(\mathrm{dG})-$ poly $(\mathrm{dC})$ sequences were inserted at the unique XhoI site between P2 and P3. The resulting construct, the pL-GEX-C/G plasmid [pL-GEX$\mathrm{C}_{n}$ or pL-GEX-G $\mathrm{G}_{n}$, depending on whether $n$ number of residues of poly $(\mathrm{dC})$ or poly(dG) sequences are on the coding strand], was employed to test transcription-dependent recombination.

On the basis of the twin-domain model (Liu and Wang 1987), the dG tracts are expected to experience negative superhelical strain after IPTG induction because Ptac is a much stronger promoter than Plac $[\mathrm{Ptac}$ is estimated to be 100 times stronger in promoter activity than Plac on the basis of the two different assay systems (deBoer et al. 1983; Borowiec and Gralla 1987)]. The recombination events between the homologous sequences in the Ptac and Plac promoter regions that occurred as a consequence of transcriptional activation induced by IPTG and the presence of the triplex forming poly(dG)poly (dC) sequences upstream of Ptac were examined. The original pGEX-2T vector contains the overexpressed $1 a c I^{q}$ allele of the lac repressor; therefore, expression of 
glutathione $S$-transferase (GST) proteins from the strong tac promoter is efficiently repressed until induction with IPTG, regardless of the lacI status of the E. coli host (Smith and Johnson 1988). We confirmed that this was also true for both the pL-GEX plasmid and pL-GEX containing poly(dG)- poly(dC) sequences: GST protein was made only after IPTG induction, and no significant difference was detected in the level of GST protein expression between $\mathrm{pL}-\mathrm{GEX}$ and $\mathrm{pL}-\mathrm{GEX}$ containing poly(dG)poly(dC) sequences (data not shown).

\section{Effects of IPTG-induced transcription on} recombination events in $\mathrm{rec}^{-}$and $\mathrm{recA}^{+}$cells

To test the effect of transcription on recombination events in these constructs, plasmid DNAs (pL-GEX, pLGEX-G ${ }_{21}$, and $\mathrm{pL}-\mathrm{GEX}-\mathrm{C}_{27}$ / were transfected into $E$. coli $\mathrm{AB} 1157$ (rec $\mathrm{A}^{+}$)- and $\mathrm{AB} 2463$ (rec $A^{-}$)-competent cells and cultured on amp-LB agar plates with or without IPTG $(0.5 \mathrm{~mm})$ at $37^{\circ} \mathrm{C}$ for $16 \mathrm{hr}$. AB2463 (recA ${ }^{-}$) cells have the same genetic background as $\mathrm{AB} 1157$ (rec ${ }^{+}$), (Howard-Flanders and Theriot 1966). To prepare plasmid DNAs, 60 colonies from agar plates were inoculated into amp-LB broth and cultured in a shaker at $37^{\circ} \mathrm{C}$ for $16 \mathrm{hr}$ without IPTG. The additional 16-hr outgrowth of the culture does not result in selection in our system as described in detail in Results (see Fig. 4, below). The EcoRV-EcoNI-digested plasmid DNAs were separated by $1 \%$ agarose gel electrophoresis and blotted to a nylon membrane (Zeta-probe, Bio-Rad). The membrane was hybridized with the ${ }^{32}$ P-labeled pL-GEX plasmid DNA. As shown in Figure 2, without IPTG induction (no transcriptional activation on Ptac and Plac), all constructs showed the original size of EcoRV-EcoNI fragments [Fig. 2, $\operatorname{IPTG}(-)$, lanes $2,4,6,8,10,12 ; 1400 \mathrm{bp}$ indicated by b]. On the other hand, after IPTG induction for $16 \mathrm{hr}$ on an agar plate, the control plasmid, pL-GEX without dG tracts, showed shorter EcoRV-EcoNI fragments in rec $A^{+}$cells [Fig. 2, IPTG $(+1$, lanes $3 ; 1200 \mathrm{bp}$ indicated by c] but not in rec $A^{-}$cells [Fig. 2, IPTG $(+1$, lane 5 ]. The plasmid constructs with poly(dG)-poly(dC) sequence insertions, $\mathrm{pL}-\mathrm{GEX}-\mathrm{C}_{27}$ and $\mathrm{pL}-\mathrm{GEX}-\mathrm{G}_{21}$, showed shorter fragments not only in rec $A^{+}$cells but also in rec $A^{-}$cells upon IPTG induction (Fig. 2, lanes 7,9,11,13; $1200 \mathrm{bp}$ indicated by $\mathrm{c}$. For pL-GEX-G $\mathrm{G}_{21}$, even shorter fragments of $400 \mathrm{bp}$ were detected as well (Fig. 2, lanes 11,13; 400 bp indicated by d). We call the deletion that led to the larger fragment of $1200 \mathrm{bp}$, type I recombination, and the shorter fragment of $400 \mathrm{bp}$, type II recombination. The results of transcriptional activation of a bacterial gene by IPTG show two important facts: A specific deletion mutation in the control pL-GEX plasmid occurs in a RecA dependent manner, and insertion of poly $(\mathrm{dG})-$ poly $(\mathrm{dC})$ sequences into the upstream region of the gene results in specific deletion mutations in a RecA independent manner. In this paper we focused on the effects of poly(dG)poly $(\mathrm{dC})$ sequences on homologous recombination in response to transcriptional activation. The mechanism for RecA dependent, transcription-induced recombination
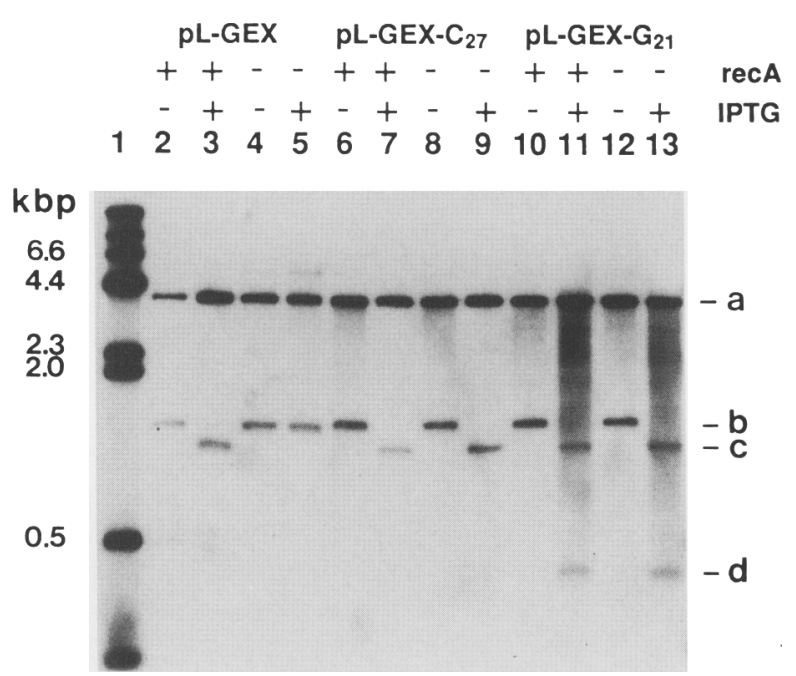

Figure 2. Detection of transcription-dependent recombination in plasmids. A 16-hr IPTG induction to activate transcription was performed on E. coli $\mathrm{AB} 1157\left(\mathrm{rec} \mathrm{A}^{+}\right)$and $\mathrm{AB} 2463\left(\mathrm{recA}^{-}\right)$ cells bearing plasmids pL-GEX, pL-GEX-C $\mathrm{C}_{27}$, and pL-GEX-G ${ }_{21}$ on amp-LB agar plates. The transfected cells were plated on amp-LB agar plates with or without $0.5 \mathrm{mM}$ IPTG. The plasmid DNAs were prepared from an overnight culture of 60 pooled colonies in amp-LB medium without IPTG. The EcoNI-EcoRV fragments were analyzed by Southern blot analysis. The blotted membrane was hybridized with ${ }^{32} \mathrm{P}$-labeled plasmid DNA, pLGEX. Restriction enzyme digestion patterns of pL-GEX, $\mathrm{pL}$ GEX- $\mathrm{C}_{27}$, and pL-GEX-G $\mathrm{G}_{21}$ plasmid DNAs are shown with $(+)$ and without $(-\mid$ IPTG induction. (Lane 1) $\lambda$ HindIII DNA size marker; (lanes 2-5) pL-GEX; (lanes 6-9) pL-GEX-C 27 ; (lanes 10 13) pL-GEX-G 21 ; (lanes $2,4,6,8,10,12$ ) IPTG(-); (lanes $3,5,7,9$, 11,13) IPTG|+); (lanes 2,3,6,7,10,11) rec ${ }^{+}$; (lanes 4,5,8,9,12, 13) $\mathrm{rec}^{-}$. (a) EcoRV-EcoNI 3800-bp fragment; (b) EcoRVEcoNI 1400-bp fragment; (c) EcoRV-EcoNI 1200-bp fragment; (d) EcoRV-EcoNI 400-bp fragment.

observed for the control pL-GEX plasmid deserves independent study and is currently under investigation.

\section{Identification of type I and type II recombination sites}

The recombination sites were analyzed by direct sequencing of the DNA fragments (EcoRV-EcoNI, 3'-labeled at the EcoNI site/ generated by type I and II recombination. We also selected 10 colonies from IPTG-induced E. coli carrying pL-GEX-C $\mathrm{C}_{27}$ or pL-GEX-G $\mathrm{G}_{21}$ to obtain type I and type II recombinants. The nucleotide sequence of pL-GEX from EcoRV to EcoNI sites is shown in Figure 3A. The poly(dG)-poly (dC) sequences were inserted into the $X$ hoI site. The sequence analysis of type I recombination ( $1200 \mathrm{bp}$ of the EcoRV-EcoNI fragment) revealed that the sequence between $\mathrm{P} 2$ and $\mathrm{P} 3$, including poly(dG)-poly(dC) or the sequence between position 1177 and 1365 was deleted. The sequence of type II recombination (400 bp of the EcoRV-EcoNI fragment) showed that the sequence between $\mathrm{P} 1$ and $\mathrm{P} 3$, including poly(dG)-poly(dC), or the sequence between position 403 and 1365 was deleted. The results indicate that the type 

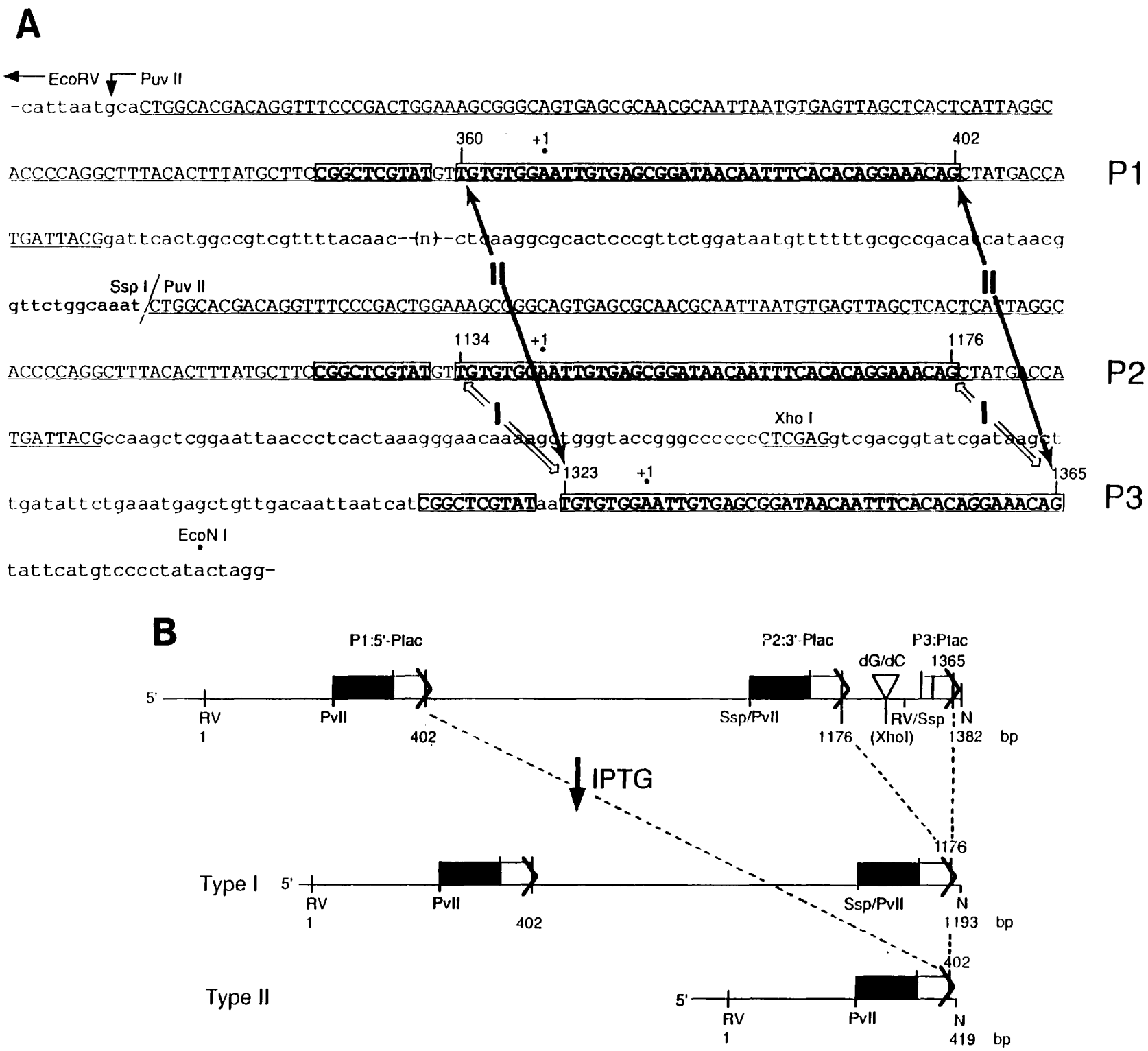

Figure 3. Analysis of recombination sites. $(A)$ Sequences of recombination sites: The nucleotide sequence of the EcoRV-EcoNI fragment of pL-GEX is shown. The nucleotide numbering starts at the 5' end of the EcoRV-cleaved sequence. The EcoNI site is located $1401 \mathrm{bp}$ away from the EcoRV site, excluding dG tracts. The identical sequences between P1 and P2 regions are underlined with uppercase letters and correspond to solid boxes in $B$. The identical sequences among P1, P2, and P3 regions are open boxed with boldface letters and correspond to open boxes in $B$. Poly $(\mathrm{dG})$-poly $(\mathrm{dC})$ sequences were introduced in the $X h o \mathrm{I}$ site as described in Materials and methods. The +1 site (the transcriptional start site) of each promoter was indicated. Double-headed open arrows (I) indicate type I recombination region between P2 and P3. Double-headed closed arrows (II) indicate type II recombination region between P1 and P3. (B) Recombination products after transcriptional activation: Plasmid sequences of pL-GEX-C/G are represented by horizontal rules. The transcription was activated by addition of IPTG and is depicted by an arrow. The analysis of plasmids after transcriptional activation resulted in two types of recombination products (type I and type II). (RV) EcoRV; (PvII) PvuII; (Ssp) SspI; (N) EcoNI; $(\mathrm{dG} / \mathrm{dC})$ poly $(\mathrm{dG})$-poly $(\mathrm{dC})$ sequence; (bp) base pairs.

I recombination ( $200 \mathrm{bp}$ deletion) occurred at the identical direct repeat sequences between position 1134 and 1176 in P2 (bold letters) and position 1323-1365 in P3 (bold letters) deleting the dG tract and the Ptac promoter. The type II recombination ( $1000 \mathrm{bp}$ deletion) occurred at the same sequences between position 360-402 in P1 (bold letters) and position 1323-1365 in P3 (bold letters) deleting all of the dG tract, 3'-Plac and Ptac promoters. Theoretically, recombination could occur at any position within identical sequences among P1, P2, and P3 as illustrated in Figure 3B. Recombination between P1 and $\mathrm{P} 2$, however, has never been detected even though these two sites share 176-bp identical sequences /uppercase letters underlined in Fig. 3A; open and closed box in Fig. 
3B). The only difference between the region $\mathrm{P} 1-\mathrm{P} 2$, which did not show recombination, and the regions $\mathrm{Pl}-$ $\mathrm{P} 3$ and P2-P3, which did show recombination, is that poly $(\mathrm{dG})-$ poly $(\mathrm{dC})$ sequences were not inserted in the region $\mathrm{P} 1-\mathrm{P} 2$, whereas poly $(\mathrm{dG})-$ poly $(\mathrm{dC})$ sequences were inserted in the regions $\mathrm{P} 1-\mathrm{P} 3$ and $\mathrm{P} 2-\mathrm{P} 3$.

\section{$\operatorname{Poly}(d G)-\operatorname{poly}(d C)$ sequences induce homologous recombination upon transcriptional activation}

The effect of the $\mathrm{dG}$ tracts on the transcription-dependent recombination was examined in more detail. We studied the frequencies of recombination for plasmid DNAs, pL-GEX and pL-GEX-G ${ }_{27}$, at varying lengths of time during IPTG treatment in liquid culture of $E$. coli $\mathrm{AB} 2463\left(\mathrm{rec}^{-}\right)$cells transfected with one of these DNAs. Bacterial cells $\left(5 \times 10^{3}\right)$ transfected with plasmid DNA were incubated in LB for $1 \mathrm{hr}$. The cells were then incubated in LB containing $0.5 \mathrm{mM}$ IPTG and ampicillin for $3,4,5,6,7,8$, or $9 \mathrm{hr}$ and incubated further for $16 \mathrm{hr}$ without IPTG. The plasmid DNAs were isolated, and the $E c o$ RV-EcoNI fragments, which were end-labeled at the $E c o N I$ site by the Klenow fragment of polymerase I, were separated on a $4 \%$ native polyacrylamide gel. To quantify the recombination frequencies in each plasmid, the intensity of the bands was measured by a densitometer, and the recombination frequencies were calculated as described in the legend to Figure 4A. As shown in Figure 4A, a poly $(\mathrm{dG})-$ poly $(\mathrm{dC})$ sequence-inserted construct (pL-GEX-G ${ }_{27}$ ) showed $50 \%$ recombination after $5 \mathrm{hr}$ [typical data are shown in Figs. 4B (lane 8) and 5A, C (lane 6)] and nearly $100 \%$ recombination after $7 \mathrm{hr}$ of exposure to IPTG. On the other hand, no trace of recombination was detected for the control plasmid pL-GEX without poly $(\mathrm{dG})-$ poly $(\mathrm{dC})$ sequence in $\mathrm{rec} \mathrm{A}^{-}$cells even after 9-hr IPTG induction in liquid culture. This is in full agreement with our earlier result that no recombination was detected in $r e c A^{-}$cells for the control plasmid isolated from the 16-hr IPTG induction on an agar plate (Fig. 2, lane 5). The growth curve for $r e c A^{-}$AB2463 cells
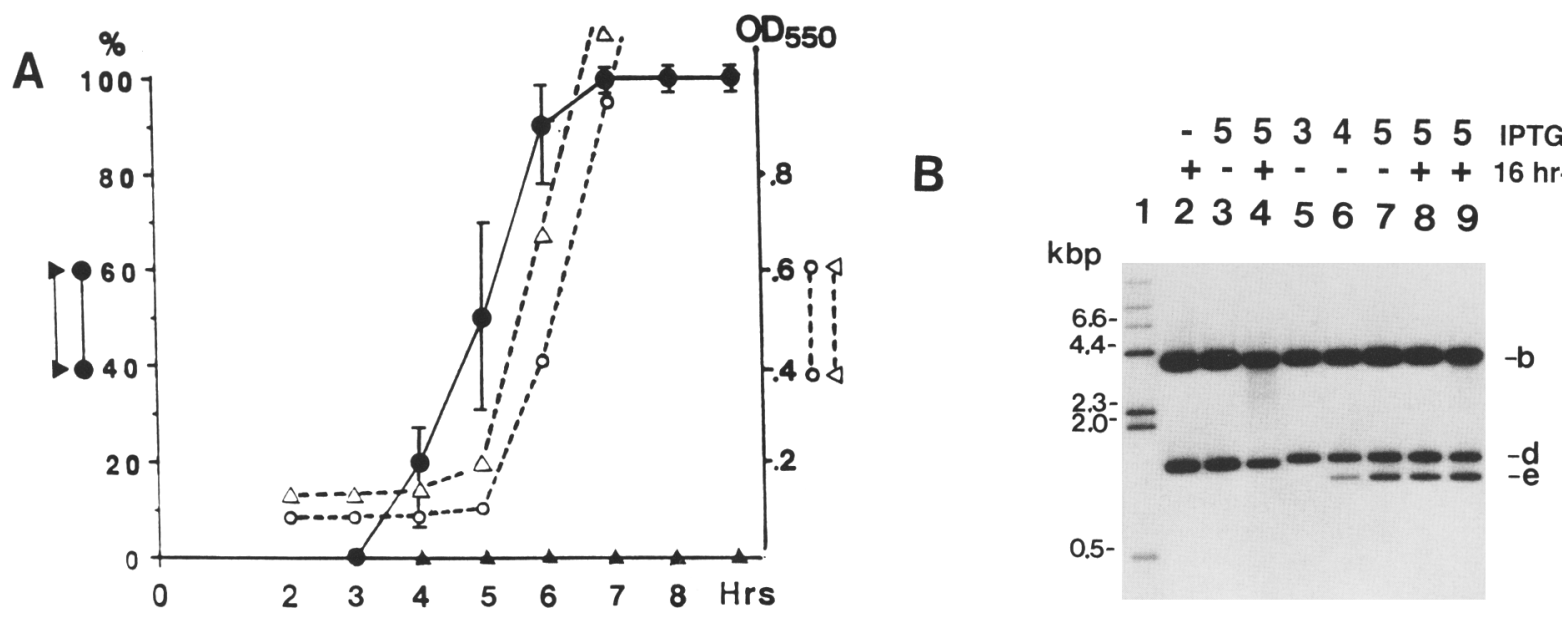

Figure 4. Recombination frequencies at various time points of IPTG exposure in recA ${ }^{-}$cells. $(A)$ Plasmid DNAs, pL-GEX, and pL-GEX-G ${ }_{27}$, were transfected into E. coli AB2463 (rec $A^{-}$) competent cells. The transfected cells were incubated at $37^{\circ} \mathrm{C}$ for $1 \mathrm{hr}$ in $3 \mathrm{ml}$ of amp-LB. IPTG was then added to a final concentration of $0.5 \mathrm{~mm}$. After the indicated incubation time with IPTG, $1 \mu \mathrm{l}$ of the IPTG-induced cultures was inoculated into $3 \mathrm{ml}$ of fresh amp-LB without IPTG and was incubated for an additional $16 \mathrm{hr}$. The bacterial growth was monitored at various time points by the $\mathrm{OD}_{550}$ measurement. The plasmid DNAs were prepared by the alkaline-lysis method followed by phenol extraction. The EcoRV-EcoNI fragments of the plasmid DNAs, end-labeled at the EcoNI site by Klenow fragment of polymerase I, were separated by a $4 \%$ native polyacrylamide gel. The intensities of EcoRV-EcoNI fragments $(1400,1200$, and $400 \mathrm{bp})$ were quantified by a densitometer from X-ray films. The frequencies of recombination (total recombination frequency: type I plus type II) were calculated as quotient of total intensity of 1200 -bp fragments (type I recombination product) and 400 -bp fragments (type II recombination product) divided by total intensity of $1400 \mathrm{bp}$ (undeleted EcoRV-EcoNI fragment), 1200-, and 400-bp fragments. Error bars indicate minimum and maximum values obtained from three experiments. $(\mathbf{A}) \mathrm{pL}-\mathrm{GEX}_{;}(\mathbf{O}) \mathrm{pL}-\mathrm{GEX}^{-\mathrm{G}_{27}}$, total recombination frequency. $(\Delta) \mathrm{pL}$-GEX; $(O) \mathrm{pL}-\mathrm{GEX}-\mathrm{G}_{27}, \mathrm{OD}_{550} \cdot(B)$ Southern blot analyses were performed on plasmid DNAs, pL-GEX and pL-GEX-G ${ }_{27}$, prepared from $E$. coli directly after IPTG induction and after an additional 16-hr incubation without IPTG. First, the $E$. coli cells bearing the plasmid DNAs were cultured overnight. Then $5 \mathrm{ml}$ of the overnight cultures were inoculated into $500 \mathrm{ml}$ of amp-LB and incubated for $2 \mathrm{hr}$. IPTG was then added to the $500 \mathrm{ml}$ cultures at $0.5 \mathrm{mM}$ and the cultures were incubated for $3-5 \mathrm{hr}$ as indicated. The plasmid DNAs were isolated directly from the $500 \mathrm{ml}$ cultures by the alkaline-SDS lysis method followed by $\mathrm{CsCl}$ density gradient centrifugation (lanes 3,6,7). In parallel, $1 \mu \mathrm{l}$ of the IPTG-induced cultures was removed after a 5-hr IPTG induction, inoculated into $3 \mathrm{ml}$ of LB without IPTG, and incubated for an additional $16 \mathrm{hr}$ (lanes 2, 4, 8, 9, indicated as + ). The plasmid DNAs were then purified by alkaline-SDS lysis followed by $\mathrm{CsCl}$ density gradient centrifugation (lane 8) or phenol extraction (lanes $4,9 \mid$ to examine total DNA not limited to the supercoiled DNA. The plasmid DNAs digested with EcoNI and EcoRV restriction enzymes were analyzed by the Southern blot method as described in Fig. 2. (Lane 1) $\lambda$ HindIII DNA size marker; (lane 2-4) pL-GEX; (lanes 5-9); pL-GEX-G 27 ; (lanes 2) IPTG (-); (lane 5) IPTG, 3 hr; (lane 6) IPTG, 4 hr; (lanes 3,4,7,8,9); IPTG, 5 hr. (b) EcoRV-EcoNI 3800-bp fragment; (d) EcoRV-EcoNI 1400-bp fragment; (e) EcoRV-EcoNI 1200-bp fragment. 


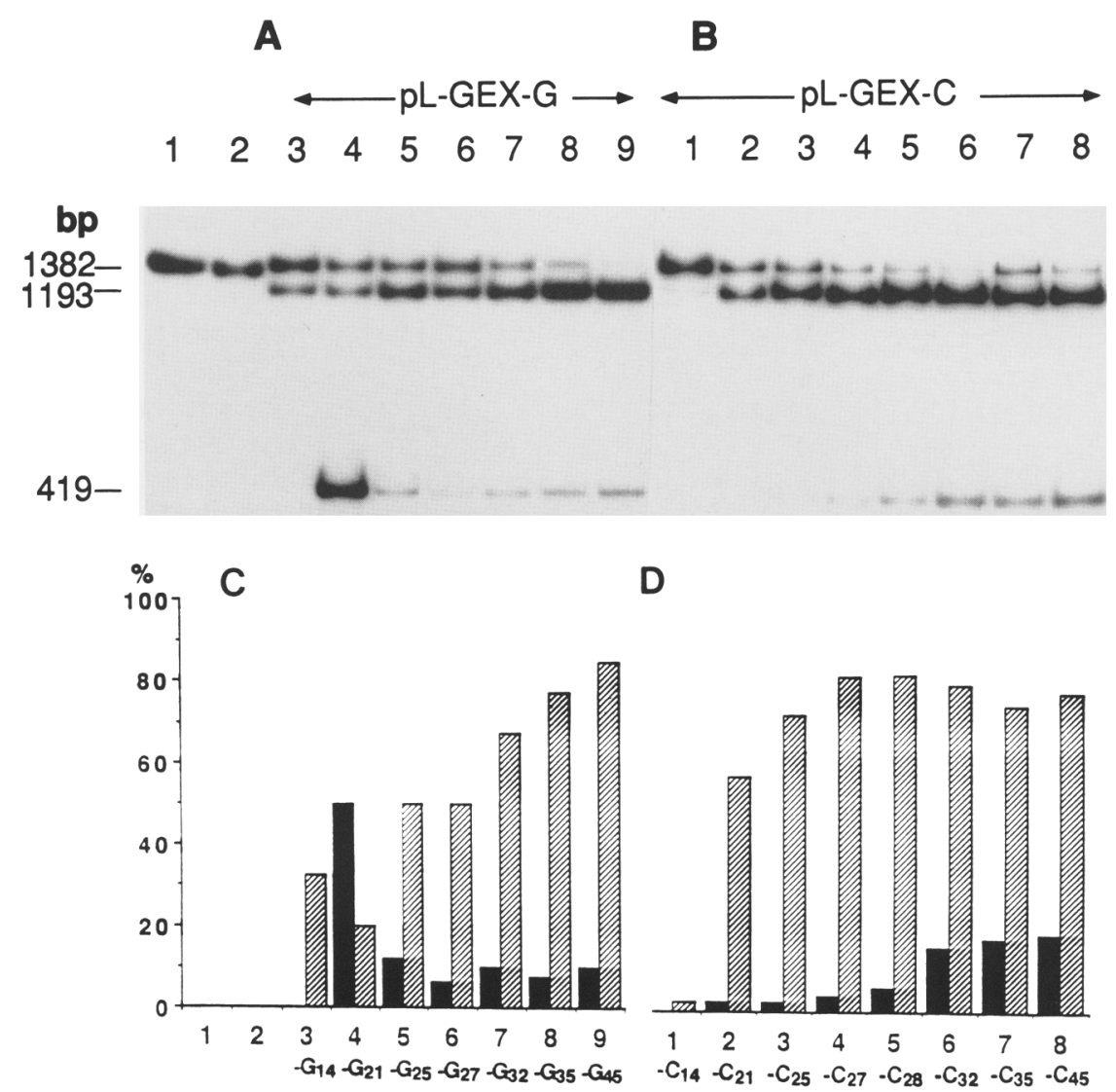

Figure 5. Quantitative analysis of recombination products in plasmids containing varying lengths of poly (dG)-poly(dC) sequences. A 5-hr IPTG induction was performed on $E$. coli $\mathrm{AB} 1157$ cells bearing plasmids $\mathrm{pL}-\mathrm{GEX}-\mathrm{C} / \mathrm{G}$. The experiments and the calculation for the frequency of recombination are as described in the legend to Fig. 4. The frequencies of type I and type II recombinations were calculated as quotient of intensity of the 1200 -bp fragment divided by total intensity of $1400-$, 1200-, and 400-bp fragments /type I recombination, hatched bar), and as quotient of $400 \mathrm{bp}$ divided by total amounts (type II recombination, solid bar). For up to $5 \mathrm{hr}$ of induction with IPTG, no trace of recombination was detected in control pL-GEX plasmid in $r e c A^{+}$cells, and there was no significant difference in recombination frequencies for a dG tract-inserted plasmid between $\mathrm{rec} \mathrm{A}^{-}$cells and $\mathrm{rec} \mathrm{A}^{-}$cells (data not shown). (A) (lane 1) pL-GEX, IPTG(-); (lane 2) pL-GEX, IPTG( +); (lanes 3-9) pLGEX-G - IPTG $\mid+$ ); (lane 3) $\mathrm{G}_{14}$; (lane 4) $\mathrm{G}_{21}$; (lane 5) $\mathrm{G}_{25}$; (lane 6) $\mathrm{G}_{27}$; (lane 7) $\mathrm{G}_{32}$; (lane 8) $\mathrm{G}_{35}$; (lane 9) $\mathrm{G}_{45}$. (B) (Lanes 1-8) pL-GEX-C ${ }_{n}$, IPTG( + ). (Lane 1) $\mathrm{C}_{14}$; (lane 2) $\mathrm{C}_{21}$; (lane 3) $\mathrm{C}_{25}$; (lane 4) $\mathrm{C}_{27}$; (lane 5) $\mathrm{C}_{28}$; (lane 6) $C_{32}$; (lane 7) $C_{35}$; (lane 8) $C_{45} \cdot(C, D)$ The calculated recombination frequency of pL-GEX-G and pL-GEX-C corresponding to $A$ and $B$. indicated that during the first 5-hr IPTG induction, the cell number remained essentially unamplified (Fig. 4A).

There might be selection of cells bearing the deleted constructs over those bearing the original construct during the 16-hr liquid culture without IPTG. During the IPTG induction step, cells containing the plasmid DNA that has the triplex structure may be lethal, and the only cells to survive the induction may be those with a preexisting deletion. Very few such cells could be amplified during the subsequent 16 -hr culture into a dense population. If this assumption is true, then one would expect to find deleted construct to be a very minute constituent of the plasmid DNA purified immediately after the induction step. Thus, the plasmid DNA purified directly after IPTG induction and after an additional growth period should give completely different restriction digestion patterns.

To check the effect of outgrowth, we compared deletion mutation between the pL-GEX-G ${ }_{27}$ DNA purified from recA- AB2463 cells immediately after a 5-hr IPTG induction and the same DNA purified from the cells after an additional 16-hr liquid culture without IPTG (outgrowth). We found that the directly purified plasmid DNAs after IPTG induction gave virtually identical results with DNAs purified from the cell culture incubated for an additional $16 \mathrm{hr}$ in terms of the frequency $(50 \%)$ and the type of deletion mutations (Fig. 4B, lanes 7,8 ). We also checked the methods of plasmid purification for the analysis of the recombination events using ethidium bromide-CsCl gradient ultracentrifugation or phenol extraction after alkaline-SDS lysis. These data also showed that the two different plasmid purifications gave the same results (Fig. 4B, lanes 8,9). Deletion mutations for the plasmid DNA purified immediately after 3- and 4-hr IPTG inductions were also examined. After a 3-hr IPTG induction, no deletion was detected. After a 4-hr IPTG induction, however, a significant portion $(20 \%)$ of the plasmid DNA showed deletion mutation. Again, these results remained unchanged after an additional incubation for $16 \mathrm{hr}$ without IPTG (Fig. 4A,B). This rules out the possibility that cells bearing the deleted constructs are selected during the additional 16-hr liquid culture. It is also unlikely that selection took place during IPTG induction because high frequencies of mutation were already detected during the 4- to 5-hr IPTG-induction period without cell amplification (Fig. 4A). Therefore, rather than selection of cells bearing pre-existing deletions, these results taken together support the notion that poly(dG)-poly(dC) sequences actively participate in the induction of homologous recombination that leads to deletion mutation when the transcription of the downstream gene is activated. 
$\operatorname{Poly}(d G)-p o l y(d C)$ sequences induce recombination in a length-and orientation-dependent manner

Poly $(\mathrm{dG})-$ poly $(\mathrm{dC})$ sequences are known to adopt intramolecular dG.dG.dC triplex structures either in purified supercoiled plasmid DNA in vitro or in E. coli cells in a length-dependent manner (Kohwi and Kohwi-Shigematsu 1991; Kohwi et al. 1992). This means that under a given superhelical density and ionic strength, poly(dG)poly $(\mathrm{dC})$ sequences longer than a minimum length adopt a dG.dG.dC triplex, and the longer the dG tracts are, the more readily a triple helix is formed. The triplex formation and the increase in recombination frequency induced by poly $(\mathrm{dG})-$ poly $(\mathrm{dC})$ sequences may be related. To test this idea, we first examined the effect of the lengths of poly (dG)-poly(dC) sequences on recombination. We employed E. coli cells carrying constructs containing varying lengths of poly $(\mathrm{dG})-$ poly $(\mathrm{dC})$ sequences and analyzed recombination frequencies in liquid culture after a 5-hr exposure to IPTG. The plasmid pL-GEX$\mathrm{G}_{n}$, where $n=14,21,25,27,32,35$, or 45 , was transfected into $E$. coli $\mathrm{AB} 1157$-competent cells. The $E$. coli cells were grown, and the plasmid DNAs were purified by phenol extraction and analyzed as described above. The control construct, pL-GEX without dG tracts, did not exhibit any recombination either, with (Fig. 5A, lane 2) or without (Fig. 5A, lane 1) IPTG induction, and only the intact EcoRV-EcoNI fragment $(1400 \mathrm{bp})$ was detected. On the other hand, for PL-GEX-G plasmids containing dG tracts of $14-45$ bp (Fig. 5A), two shorter EcoRV-EcoNI fragments appeared, which reflect type I and type II recombination upon induction with IPTG (Fig. 5A, lanes 4-9). For up to $5 \mathrm{hr}$ of induction with IPTG, no trace of recombination was detected in control pL-GEX plasmid in recA ${ }^{+}$cells, and there was no significant difference in recombination frequencies for a dG tract-inserted plasmid between $r e c A^{+}$cells and $r e c A^{-}$ cells (data not shown).

The results shown in Figure 5 indicate that type $I$ and type II recombinations exhibit dG tract length dependency. The type I recombination (200 bp deletion) was induced by a short dG tract of $14 \mathrm{bp}\left(\mathrm{pL}-\mathrm{GEX}-\mathrm{G}_{14}\right)$ such that $30 \%$ of the plasmid population was deleted (Fig. $5 \mathrm{~A}, \mathrm{C}$, lanes 3). The total recombination frequency increased as the dG length increased, and nearly $100 \%$ deletion was obtained with a long dG tract of $45 \mathrm{bp}$ (Fig. $5 \mathrm{~A}, \mathrm{C}$, lanes 9). The type II recombination (1000-bp deletion) was dramatically enhanced for a dG tract of $21 \mathrm{bp}$, which resulted in a $50 \%$ frequency (Fig. 5A,C, lanes 4). For longer dG tracts, the type II recombination was detected at a low level not exceeding $10 \%$ (Fig. 5A,C, lanes $5-9 \mid$.

The effect of orientation of poly $(\mathrm{dG})-$ poly $(\mathrm{dC})$ sequences on homologous recombination was also examined. A similar experiment was done with the plasmids (pL-GEX-C) containing varying lengths of poly(dG)poly $(\mathrm{dC})$ in the opposite orientation from the pL-GEX-G construct described above. Although pL-GEX-C showed very high frequency of type I recombination (Fig. 5B,D), there were some differences between $\mathrm{pL}-\mathrm{GEX}-\mathrm{C}$ and $\mathrm{pL}$ -
GEX-G. One major difference was found in the lengthdependent type II recombination. Although the type II recombination (1000-bp deletion) was detected at very low frequency $(<5 \%)$ up to 28 bp for pL-GEX-C (Fig. $5 B, D$, lanes $2-5$ ), a much higher frequency of $50 \%$ was detected for pL-GEX-G ${ }_{21}$ (Fig. 5A,C, lanes 4). Such high frequency of type II recombination was never observed for pL-GEX-C at any length of the dC tracts (Fig. 5B,D). Another difference between pL-GEX-C and pL-GEX-G was that the type I recombination occurred at high frequency $(30 \%)$ even for pL-GEX-G ${ }_{14}$ (Fig. 5A,C, lanes 3 ), although no recombination was detected for $\mathrm{pL}-\mathrm{GEX}-\mathrm{C}_{14}$ (Fig. 5B,D, lanes 1). Thus, the pL-GEX-G construct is more prone to undergo type I recombination than the pL-GEX-C construct for short poly(dG)-poly (dC) tracts.

These results show that insertion of the poly(dG)poly $(\mathrm{dC})$ sequences in either orientation results in high levels of recombination frequencies between the two direct repeats separated by either 200 or $1000 \mathrm{bp}$. The level and the type of recombination, however, depend on both the length and the orientation of the poly $(\mathrm{dG})-$ poly $(\mathrm{dC})$ sequences. Both recA ${ }^{+}$and $r e c A^{-}$cells, after a 5 -hr exposure to IPTG, revealed virtually identical results on the $\mathrm{dG}$ length-dependent recombination /data not shown).

\section{Recombination is independent of phasing of the $d G$ tracts}

In site-specific recombination of $\lambda$ phage and $E$. coli DNA, it is known that IHF bends DNA, and recombination is sensitive to phasing of the bent DNA (Goodman and Nash 1989; Snyder et al. 1989). In our homologous recombination system, it is also possible that a protein that binds to the dG tract participates in recombination by inducing a bend at the dG tract. If so, phasing of the dG tract relative to the Ptac promoter might affect recombination rates. To test this idea, the distance between the $3^{\prime}$ end of the dG tracts and +1 site was varied by inserting random-sequence oligomers of varying lengths. The $3^{\prime}$ end of the dG tract in pL-GEX-C $\mathrm{C}_{27}$ is located at -87 from the +1 site of the Ptac. The other four plasmid DNAs constructed have 82-, 92-, 108-, and 119-bp distances from the +1 site of the Ptac (P3). The recombination frequencies were analyzed as described in the legend to Figure 4A. As shown in Figure 6, the plasmid DNAs with a half helical turn difference $\langle-5 \mathrm{bp}$, lane $1 ;+5 \mathrm{bp}$, lane 3 ) from the original pL-GEX-C ${ }_{27}$ (lane 2) showed the same recombination frequency. Moreover, the plasmid DNAs with the same phasing as pL-GEX$\mathrm{C}_{27}$ but longer spaces (+10 bp, lane $4 ;+21 \mathrm{bp}$, lane 5; $+32 \mathrm{bp}$, lane 6) also showed virtually the same frequency. Therefore, the homologous recombination mediated by the $\mathrm{dG}$ tracts does not display the DNA turn dependence seen in site-specific recombination (Goodman and Nash 1989) or in the transcriptional activation of the SV40 DNA early promoter in a eukaryotic system (Takahashi et al. 1986). Also, in the absence of poly(dG)poly $(\mathrm{dC})$ sequences, none of the random sequences em- 


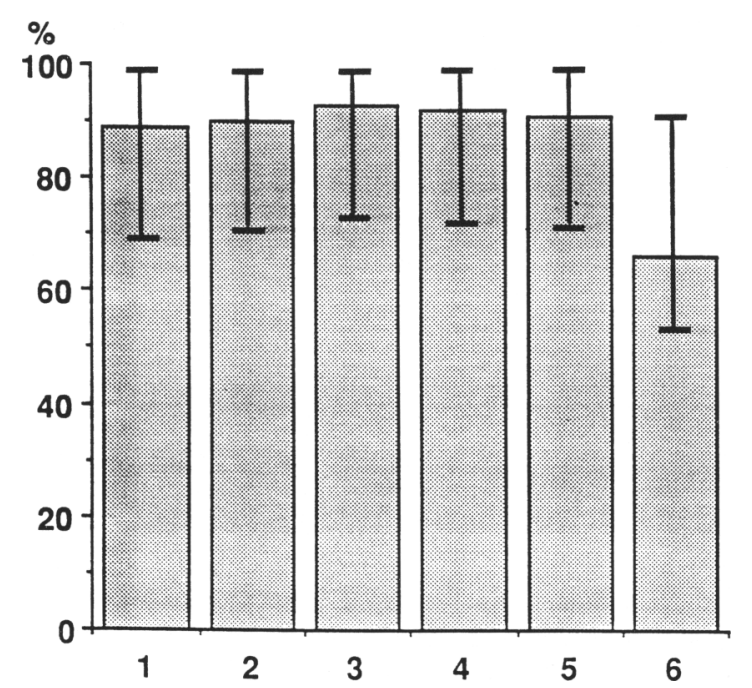

Figure 6. Phasing effect of the dG tracts relative to the Ptac on recombination. Varying lengths of random sequences were introduced between Ptac promoter and dG tracts in pL-GEX- $\mathrm{C}_{27}$. Those DNAs were subjected to the recombination analysis with IPTG induction, and total recombination frequencies were calculated as described in the legend to Fig. 4 . The distance of the space was counted from the +1 site of the Ptac promoter to the $3^{\prime}$ end of the poly (dG)-poly $(\mathrm{dC})$ sequence. Error bars indicate minimum and maximum values obtained from three experiments. (Lane 1) 82 bp; (lane 2) 87 bp (original pL-GEX-C . $_{27}$; (lane 3) $92 \mathrm{bp}$; (lane 4) $97 \mathrm{bp}$; (lane 5) 108 bp; (lane 6) $119 \mathrm{bp}$.

ployed in this experiment to alter the distance stimulated recombination (data not shown).

\section{Transcription-induced dG.dG.dC triplex structure is detected in $\mathrm{E}$. coli cells}

Insertion of poly(dG)-poly(dC) tracts between homologous sequences induces recombination of these sequences after transcriptional activation of a downstream gene in $r e c A^{-}$cells. We infer from these results that negative superhelical strain accumulated by active transcription of a gene stabilizes the formation of an intramolecular dG.dG.dC triplex structure by poly(dG)poly $(\mathrm{dC})$ sequences, which consequently brings remote sequences together to stimulate recombination. If this is the case, we should be able to detect the dG.dG.dC triplex formation in $E$. coli cells in a transcription-dependent manner. To detect the triplex in $E$. coli cells, we employed chloroacetaldehyde (CAA), an analog of bromoacetaldehyde (BAA), which specifically detects unpaired adenine and cytosine bases. These chemicals have been used for detecting non-B DNA structures including intramolecular triple helices both in vitro and in vivo (for review, see Kohwi-Shigematsu and Kohwi 1992). When poly(dG)-poly(dC) sequences form a dG.dG.dC triplex, cytosines over the $5^{\prime}$ half of the dC tract that are not involved in the triplex formation are unpaired and are reactive with CAA. Thus, dG.dG.dC triplex formation can be demonstrated by the cleavages of DNA at these CAA-reacted cytosine residues, as shown by the appearance of new bands within sequencing ladders. An intramolecular dG.dG.dC triplex, which forms only under negative superhelical strain, was detected previously in $E$. coli cells after chloramphenicol treatment when maximal unconstrained superhelical density was achieved (Kohwi et al. 1992).

We anticipated that the recombination might proceed rapidly once a dG.dG.dC triplex forms and that these two events might be coupled. Therefore, to detect a transcription-dependent dG.dG.dC triplex formation in $E$. coli cells at any given time point, we employed P1- and P2-deleted plasmid DNAs that were derived from $\mathrm{pL}$ GEX-C DNAs $\left(\mathrm{p} \Delta\right.$-GEX- $\mathrm{C}_{14},-\mathrm{C}_{21},-\mathrm{C}_{27},-\mathrm{C}_{32}$, and $\left.-\mathrm{C}_{35}\right)$ so that recombination could not take place even in a $5-\mathrm{hr}$ IPTG induction. As shown in Figure 7, no CAA reacted sites were detected in $\mathrm{dC}$ tracts in the negative control (Fig. 7, lane 8 ; p $\Delta$-GEX-C ${ }_{35}$, without IPTG induction or chloramphenicol treatment, but with CAA treatment). On the other hand, the plasmid p $\Delta-$ GEX-C ${ }_{35}$ DNA in $E$. coli cells treated with chloramphenicol (Fig. 7, lane 7) showed a typical CAA reaction pattern, indicating a dG.dG.dC triplex formation, such that cytosine residues

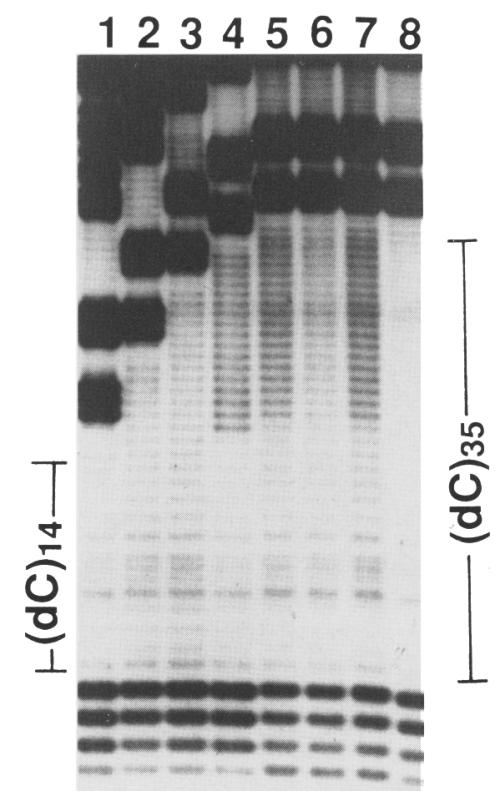

Figure 7. Detection of a dG.dG.dC triplex structure in E. coli cells. Plasmid DNAs modified with CAA in situ were prepared as described in Materials and methods. The HindIII-EcoRV fragments, $3^{\prime}$-end radiolabeled at the HindIII site / dC tracts were labeled), were treated with formic acid and subsequently cleaved by piperidine (Maxam and Gilbert 1980). CAA-treated $\mathrm{dC}$ residues over the $5^{\prime}$ half of the $\mathrm{dC}$ tract were detected as new cleavage sites in the purine ladder. This pattern of CAA reactivity indicates the intramolecular dG.dG.dC triplex formation (Kohwi and Kohwi-Shigematsu 1988; Kohwi et al. 1992). (Lanes 1-5) IPTG, 3 hr; (lane 6) IPTG, 5 hr; (lane 7) chloramphenicol, 2 hr; (lane 8) noninduced control. (Lane 1) $\mathrm{p} \Delta-\mathrm{GEX}_{\mathrm{C}} \mathrm{C}_{14}$; (lane 2) $\mathrm{p} \Delta$-GEX-C 21 ; (lane 3) $\mathrm{p} \Delta-\mathrm{GEX}-\mathrm{C}_{27}$; (lane 4) $\mathrm{p} \Delta-\mathrm{GEX}-\mathrm{C}_{32}$; (lanes 5-8) $\mathrm{p} \Delta-\mathrm{GEX}-\mathrm{C}_{35}$. 
over the $5^{\prime}$ half of poly $(\mathrm{dC})$ sequence were CAA modified and cleaved by the formic acid/piperidine reaction (Kohwi and Kohwi-Shigematsu 1988; Kohwi et al. 1992). When the same plasmid DNA was treated with IPTG for $3 \mathrm{hr}$ in vivo, it showed the same CAA reaction pattern (Fig. 7, lane 5) as seen in the chloramphenicol-treated positive control (Fig. 7, lane 7). This CAA reaction pattern for dG.dG.dC triplex formation in $E$. coli cells was also observed in a 3-hr IPTG induction in 32-bp length (Fig. 7, lane 4) but not in 27-bp length (Fig. 7, lane 3), 21-bp length (Fig. 7, lane 2) or 14-bp length (Fig. 7, lane 1) DNA fragments. A 5-hr IPTG induction, however, reduced CAA reactivity (Fig. 7, lane 6). Similar prolonged induction with chloramphenicol also failed to detect a dG.dG.dC triplex, suggesting that superhelical environment suitable for the triplex formation is transient /data not shown). The data indicate that the transcriptional activation induces dG.dG.dC triplex formation in vivo. This demonstrates that negative superhelical strain is created as a result of transcriptional activation of the downstream gene. The data also suggest that the population of $E$. coli having the triplex structure in vivo may be small at any given time, and detection of the triplex for shorter dG tracts may be difficult. The triplex formation is an earlier event than recombination, which shows a sharp rise after a 4-hr IPTG induction and achieves much higher frequency after $5 \mathrm{hr}$ (Fig. 4A). Thus, these two events do not seem to be temporally coupled. The delay in the recombination event may be caused by the time required for the actual recombination to take place after a full assembly of the recombinational machinery.

\section{Discussion}

Transcription results in the triplex formation and homologous recombination in $a$

RecA-independent manner

We employed poly (dG)-poly $(\mathrm{dC})$ sequences that form an intramolecular triplex structure in response to negative supercoiling to study whether a non-B DNA structure formation mediates homologous recombination stimulated by transcription. We have shown that by inserting poly(dG)-poly(dC) sequences between direct repeats in the $5^{\prime}$ region of the promoter, the transcriptional activation of a bacterial gene induces homologous recombination of its upstream sequences in a RecA-independent manner. In the absence of poly $(\mathrm{dG})$-poly $(\mathrm{dC})$ sequences, no recombination was induced by transcription in $r e c A^{-}$ cells.

Direct chemical probing showed that an intramolecular dG.dG.dC triplex forms in vivo after transcriptional activation (Fig. 7). This structure was detected previously in $E$. coli cells only under high unconstrained negative superhelical density achieved after chloramphenicol treatment (Kohwi et al. 1992). This shows that a local negative superhelical strain is created by transcriptional activation of a gene and stabilizes a triple helix in the $5^{\prime}$ region, in agreement with the twin-supercoiling model proposed by Liu and Wang (1987). The intramolecular dG.dG.dC triplex formation results in a sharp folding of the DNA. Therefore, this structure could bring remote sequences into close proximity to induce recombination (models shown in Fig. 8).

To examine possible involvement of RecA protein in our recombination system, we studied recombination events using several recA $A^{-} E$. coli strains, in addition to $\mathrm{AB} 2463$ (with the same genetic background as $\mathrm{AB} 1157$ $r e c A^{+}$, $\mathrm{HB} 101$, and DH5 $\alpha$. In rec $A^{-}$cells, transcriptioninduced recombination was observed only in the poly(dG)-poly(dC) sequence-inserted construct, pL-GEX$\mathrm{C} / \mathrm{G}$, and not in the control pL-GEX plasmid. It is conceivable that when two homologous sequences are aligned by sharp folding of DNA as a result of intramolecular triplex formation, RecA may no longer be needed to initiate DNA pairing. There are other studies describing recombinations that occur in rec $A^{-}$cells (for review, see Clark and Low 1988; Petes and Hills 1988). Such recombination involves short regions of homologies and is thought to proceed by another pathway such as slippage of pairing during DNA replication, or illegitimate recombination events catalyzed by gyrase (Albertini et al. 1982; Marvo et al. 1983; Chiba et al. 1989). The RecA independent homologous recombination that we have studied appears to be mediated by the non-B DNA structure formation.

\section{Model for homologous recombination mediated by transcription-induced triplex}

The model for the role of the triplex formation in recombination is presented in Figure 8 (a double-stranded form of poly(dG)-poly (dC) sequence is shown by an open triangle, and a triple-helix form is shown by a solid triangle). When the Ptac promoter (P3) is activated by IPTG induction, the negative superhelical strain accumulates at the $5^{\prime}$ region of the promoter [Fig. $8(2)$; Liu and Wang 1987) and induces a poly(dG)-poly(dC) sequence to form a triple-helix structure [Fig. $8(2)]$. The intramolecular triplex forms via sharp folding of DNA into halves. This would bring distant sequences into close proximity enabling them to align so that either type I or type II recombination is promoted [Fig. 8 (3), I or II, respectively]. The stability of the dG.dG.dC triplex increases as the length of the $\mathrm{dG}$ tract increases. Therefore, the length dependency of the dG tracts on recombination frequency supports the idea that the triplex formation induces recombination [Figs. 5 and 8 (3)].

We have also shown orientation dependency for the effect of poly (dG)-poly(dC) sequences on homologous recombination. A significant level of type I recombination was detected even for the $\mathrm{pL}-\mathrm{GEX}-\mathrm{G}_{14}$ containing a short $\mathrm{dG}$ tract of $14 \mathrm{bp}$, but there was no recombination in the comparable construct containing a dC tract of $14 \mathrm{bp}$ (Fig. $5 A, C$, lanes 3 for $-G_{14}$; Fig. $5 B, D$, lanes 1 for $-C_{14}$ ). The $\mathrm{dG}_{21}$-containing construct, $\mathrm{pL}-\mathrm{GEX}-\mathrm{G}_{21}$, revealed a substantially high level of type II recombination not found in pL-GEX-C ${ }_{21}$ (Fig. 5A,C, lanes 4 for $-\mathrm{G}_{21}$; Fig. 5B,D, 

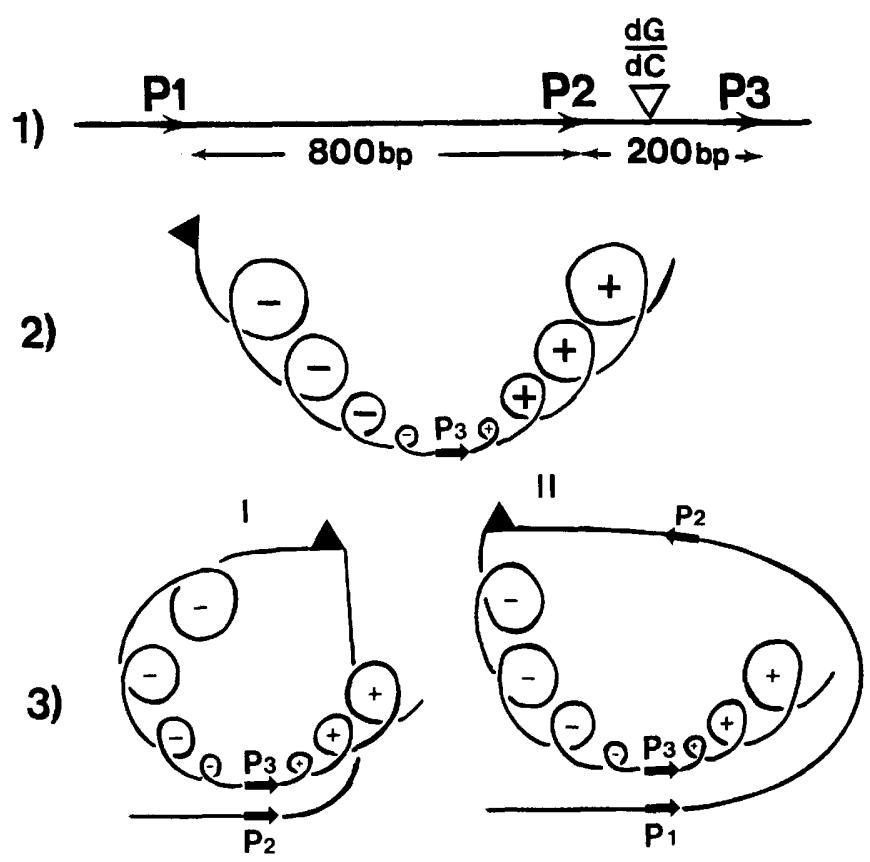

4)

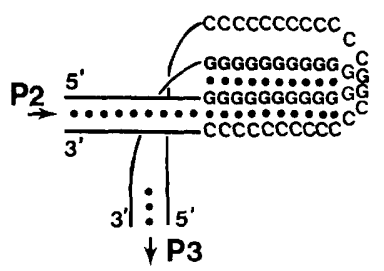

A

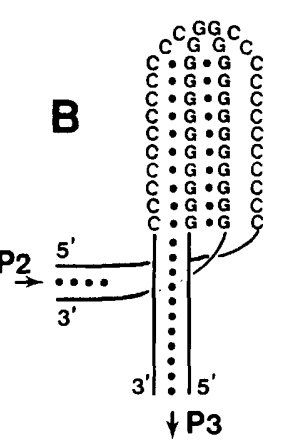

lanes 2 for $\left.-C_{21}\right)$. How could this be explained? The inherent nature of poly $(\mathrm{dG})-$ poly $(\mathrm{dC})$ sequences that induce DNA unpairing in a unidirectional manner may play an important role. Once the dG.dG.dC triplex forms, the remaining $5^{\prime}$ half of cytosine residues that do not form the triplex are exposed and unpaired. This induces unpairing in the neighboring region $5^{\prime}$ of the poly $(\mathrm{dC})$ residues. The $5^{\prime}$ half of cytosine strand and the complementary $3^{\prime}$ half of the guanine strand that forms a triplex must change their mutual orientation in space so that they can be base-paired again in the $3^{\prime}$ neighboring region of the dG tracts [Fig. $8(4)$; Kohwi and KohwiShigematsu 1988]. The extent of unpairing depends on the $d G$ tract length: The longer the $d G$ tract is, the more neighboring sequences become unpaired (Kohwi-Shigematsu and Kohwi 1985). This unidirectional unpairing is illustrated in Figure 8 (4A) for pL-GEX-G and in Fig. 8 (4B) for pL-GEX-C. It is possible that the pL-GEX-G construct with an optimal dG length $\left(\mathrm{dG}_{21}\right)$ induces baseunpairing or unwinding just upstream of the Ptac promoter. This may stimulate transcription because baseunpairing at an appropriate position might help RNA
Figure 8. Model for type I and type II recombination. Plasmid DNAs of pL-GEX-C/G are represented by horizontal rules (1). $\mathrm{P} 1, \mathrm{P} 2$, and $\mathrm{P} 3$ represent the homologous sequences of $5^{\prime}-1 a c$, $3^{\prime}-1 a c$, and tac promoters, respectively, as indicated by open boxes in Fig. $3 A$. $(\triangle)$ Double-stranded poly $(\mathrm{dG})$-poly $(\mathrm{dC})$ sequences. Once the Ptac promoter is activated by IPTG, two supercoiled domains of opposite signs are generated: A positively supercoiled domain is formed in front of the transcribing RNA polymerase [at the $3^{\prime}$ regions of $\left.\mathrm{P} 3(+)\right]$, and a negatively supercoiled domain is formed behind [at the $5^{\prime}$ regions, $(-)(2)$ twin-domain model by Liu and Wang 1987]. When negative torsional strain accumulates in the region containing poly $(\mathrm{dG})-$ poly $(\mathrm{dC})$ sequence, a dG.dG.dC triplex is formed [2 and $3,(\mathbf{A})]$. The triplex formation brings $\mathrm{P} 2$ and $\mathrm{P} 3$ that are 200 bp apart into close vicinity to stimulate recombination [type I recombination, $3(I)]$. The triplex formation also brings $\mathrm{P} 1$ and $\mathrm{P} 3$ separated by $1000 \mathrm{bp}$ close together to stimulate recombination [type II recombination $3(I I)]$. For the pL-GEX-G construct, where dG tracts are on the coding strand with respect to the Ptac promoter (P3), the dG.dG.dC triplex formation affects unpairing on $\mathrm{P} 3$ region unidirectionally $(4 A)$. Depending on the extent of the unpairing induced by the $\mathrm{dG}$ tracts, one could have stimulation or attenuation of transcription. For example, an optimal dG length $\left(\mathrm{dG}_{21}\right)$ may induce base-unpairing just upstream of the Ptac promoter, which might help RNA polymerase to initiate transcription. This would result in more active transcription and lead to more superhelical strain $5^{\prime}$ of the gene to stabilize the triplex. Any longer dG tracts may cause more extensive unpairing within the Ptac promoter and this might result in partial inactivation of the Ptac promoter. For the pL-GEX-C construct, where $\mathrm{dC}$ tracts are on the coding strand, dG.dG.dC triplex formation creates unpairing at opposite side of the $\mathrm{dC}$ tract from P3 $(4 B)$. The activity of the Ptac promoter may not be affected by unpairing of the triplex formation. Therefore, in this case, the frequency of recombination is more a direct reflection of the propensity of the triplex formation, which is in turn dependent on the dG tract length. (O) Hydrogen bonds in the triplex and in the neighboring sequences.

polymerase to initiate transcription. It has been demonstrated that DNA relaxation in the -10 region in a $g y r$ gene promoter is responsible for the stimulation of transcription (Menzel and Gellert 1987). For the pL-GEX-G ${ }_{21}$ construct, an increase in transcription rate may be achieved by this mechanism. If so, this would increase the superhelical strain $5^{\prime}$ of the gene, which in turn stabilizes the triplex, more, and result in a higher frequency of recombination. This would not be possible for $\mathrm{pL}$ GEX-C $\mathrm{C}_{21}$, which promotes base-unpairing distal from the promoter. As the length of the $\mathrm{dG}$ tracts increases in pL-GEX-G constructs, the structural effect would extend more into the promoter region and could result in transcriptional attenuation. This effect may be counterbalanced by the increase in stability of the triplex as the $\mathrm{dG}$ length increases. The orientation dependency of the poly (dG)-poly(dC) sequences on recombination could also be explained by the possibility that a triplex in the pL-GEX-G construct in which the unpaired region is proximal to the promoter may be easier to form. This may explain why pL-GEX-G $\mathrm{G}_{14}$ show recombination but not pL-GEX-C 14 . 


\section{Biological consequences of transient supercoiling generated by transcription}

Although DNA supercoiling of opposite signs generated by the process of transcription is transient in nature, this could exert a variety of effects on biological processes and functions involving DNA. Clark and Felsenfeld $(1991,1992)$ proposed a model showing that in the case of mammalian cells, the histone octamer is transferred from the positively supercoiled DNA in the path of the transcribing polymerase to the negatively supercoiled DNA behind it. This was based on the observation that nucleosome cores are much more stable on negatively supercoiled DNA compared with positively supercoiled DNA. The twin-supercoiled-domain model also predicts that promoters in the same topological domain may influence one another via local effects on DNA supercoiling. In E. coli, such a notion of one promoter controlling the activity of a second promoter provides an explanation for the anomalous regulation of the $1 e u-500$ promoter (Lilley and Higgins 1991).

Non-B DNA structures, such as left-handed Z-DNA and cruciform structures, are known to form in $E$. coli cells or in vitro as a consequence of supercoiling generated by transcription (Droge and Nordheim 1991; Dayn et al. 1992; Rahmouni and Wells 1992). Previously, we reported results suggesting that the DNA structure altered by local supercoiling can affect the level of transcription in mammalian cells (Kohwi and Kohwi-Shigematsu 1991). When placed $5^{\prime}$ of a reporter gene, the triplex-forming poly(dG)-poly(dC) sequences augmented the level of transcription in mammalian cells in a lengthdependent manner. In vivo competition assay suggests that a trans-acting factor binds a double-stranded poly (dG)-poly(dC) sequence but not when it is forming a triplex. The observation that a dG tract of 25- to $30-\mathrm{bp}$ enhanced transcription, but one of $>32$ bp abruptly abolished this enhancement, strongly suggested that an altered DNA structure could affect the level of transcription.

In this study, we have not only demonstrated transcription-induced intramolecular dG.dG.dC triplex formation in E. coli cells but also transcription-induced homologous recombination of upstream sequences mediated by the presence of poly $(\mathrm{dG})-$ poly $(\mathrm{dC})$ sequences. This model experiment may provide an important biological implication: Sequences that readily form non-B DNA structures under superhelical strain can be responsible for stimulating homologous recombination of the flanking sequences in response to transcription of nearby genes. It is important to mention that even in a wild-type DNA topoisomerase background, triple-helix structure formation and subsequent recombination events are established by transient local supercoiling generated by transcriptional activation before topoisomerases relax the DNA. Not all non-B DNA structures would stimulate recombination. Depending on the exact nature of the structure, the effect would be different. For example, in some cases, it could keep homologous sequences apart to inhibit recombination. A fused or double triple helix
(Kohwi-Shigematsu and Kohwi 1991; later called a nodule structure by Panyutin and Wells 1992), if formed in vivo, would keep $5^{\prime}$ and $3^{\prime}$ neighboring sequences apart. Because there are many stretches of sequences that form different types of non-B DNA structures, it is likely that transcription-stimulated recombination is mediated by some of those sequences in vivo.

\section{Materials and methods}

\section{Plasmids}

Plasmid DNA, pGEX-2T was purchased from Pharmacia. Plasmid DNA, Bluescript II KS + was purchased from Stratagene, and the EcoRV-PvuII fragment containing the lac promoter was subcloned into $S s p I$ site of the pGEX-2T, which was partially digested. The new construct, which contained the pGEX-2T Ptac promoter and the Bluescript lac promoter in the same direction, was selected and named as pL-GEX. Various lengths of poly $(\mathrm{dG})-$ poly $(\mathrm{dC})$ sequences were introduced into the plasmid

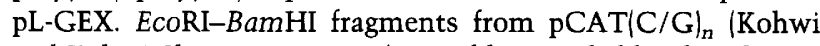
and Kohwi-Shigematsu, 1988) were blunt-ended by the Klenow large fragment and inserted at a blunt-ended $\mathrm{XhoI}$ site of $\mathrm{pL}$ GEX. Plasmids pL-GEX-G and pL-GEX-C indicate either the dG tract on the top strand or the $\mathrm{dC}$ tract on the top strand with respect to the Ptac promoter, respectively. To change the length between dG tracts and Ptac promoter, SalI and HindIII fragments generated by synthetic oligomers [TCGACGGATAAGCT (Fig. 6, lane 1); TCGACGGATCAGACTCGATAAGCT (Fig. 6, lane 3); TCGACGGATCAGACATGACTCGATAAGCT (Fig. 6, lane 4); TCGACGGATCAGACATGACCGCTTGACATGTCGATAAGCT (Fig. 6, lane 5); TCGACGGATCAGTACTCACGCAGACATGACCGCTTGACATGTCGATAAGCT (Fig. 6, lane 6)] were inserted in the SalI-HindIII sites of pL-GEX-C ${ }_{27}$.

\section{Deletion mutation assay of recombination events}

Plasmid DNAs, pL-GEX, pL-GEX-C, and pL-GEX-G, were transfected into $E$. coli $\mathrm{AB} 1157$ (recA ${ }^{-}$) or AB2463 cells (recA ${ }^{-}$, with the same genetic background as $\mathrm{AB} 1157 \mathrm{rec} A^{+}$, HowardFlanders and Theriot 1966; Moriya et al. 1988). Both cells were kindly provided by Drs. M. Moriya and A.P. Grollman. The transfected cells were incubated at $37^{\circ} \mathrm{C}$ for $1 \mathrm{hr}$ in $3 \mathrm{ml}$ of amp-LB, and IPTG was then added to the cultures at a $0.5 \mathrm{~mm}$ of final concentration. After incubation for the time indicated in the figures, typically $5 \mathrm{hr}, 1 \mu \mathrm{l}$ of the IPTG-induced cultures was inoculated to $3 \mathrm{ml}$ of fresh amp-LB and incubated at $37^{\circ} \mathrm{C}$ for 16 hr without IPTG. The plasmid DNAs were prepared from the overnight cultures by the alkaline-SDS method (Maniatis et al. 1982). The purified plasmid DNAs were labeled at the EcoNI site by the Klenow large fragment and $\left[\alpha^{-32} \mathrm{P}\right] \mathrm{dATP}$ followed by digestion with the EcoRV. The EcoNI-EcoRV fragments were separated by $4 \%$ native polyacrylamide gel electrophoresis. The intensities of the radioactivity of the fragments were quantified by a densitometer (LKB UltroscanXL) from X-ray films. For sequence analysis, the EcoNI-EcoRV fragments were isolated from the native polyacrylamide gel and subjected to the Maxam-Gilbert chemical reaction (Maxam and Gilbert 1980) by use of formic acid/piperidine (for $\mathrm{dG}$ and $\mathrm{dA}$ detection).

\section{Southern blot analysis}

Plasmid DNAs were digested with EcoNI and EcoRV. The digested DNAs were analyzed by the method of Southern (1975). The DNAs were separated by $1 \%$ agarose gel and blotted onto 
the nylon membrane (Zeta-probe, Bio-Rad) by alkaline transfer. The blotted membrane was UV cross-linked by Stratalinker2400 and hybridized in $50 \%$ formamide in a roller bottle (Hoefer Scientific Instruments) at $42^{\circ} \mathrm{C}$ with ${ }^{32} \mathrm{P}$-labeled plasmid DNA, pL-GEX, and washed with $0.2 \times$ SSC $(20 \times$ SSC: 175.3 grams of sodium chloride, 88.2 grams of sodium citrate per liter at $\mathrm{pH}$ $7.0)$ and $0.1 \%$ SDS at $68^{\circ} \mathrm{C}$ for $1 \mathrm{hr}$.

\section{Analysis of triplex structure in E. coli cells}

P1-P2 sequence-deleted plasmid DNAs were constructed from pL-GEX-C ${ }_{n}$ plasmid DNAs. Briefly, the P2 sequence was removed first by KpnI and BspMI digestion and religation, and then the P1 sequence was removed by the method of oligonucleotide mediated PCR with NarI and Bsu36 sites. The new deletion plasmid DNAs, $\mathrm{p} \Delta$-GEX-C $\mathrm{C}_{14}, \mathrm{p} \Delta$-GEX-C $\mathrm{C}_{21}, \mathrm{p} \Delta$-GEX$\mathrm{C}_{27}, \mathrm{p} \Delta-\mathrm{GEX}-\mathrm{C}_{32}$, and $\mathrm{p} \Delta-\mathrm{GEX}-\mathrm{C}_{35}$, no longer have extensive homologous sequences, but poly(dG)-poly(dC) and P3 sequences remain intact $(\sim 550 \mathrm{bp}$ shorter than the original). To detect dG.dG.dC triple-helix structure in vivo, we employed the method of Kohwi et al. (1992). Briefly, AB1157 E. coli cells carrying each $\mathrm{p} \Delta-\mathrm{GEX}-\mathrm{C}_{n}$ plasmid DNA were grown for $2 \mathrm{hr}$ in M9 media supplemented with casamino acids. The transcription was then induced with $0.5 \mathrm{~mm}$ of IPTG for 3 or $5 \mathrm{hr}$. E. coli cells were washed with phosphate-buffered saline (PBS) with $2 \mathrm{~mm}$ $\mathrm{MgCl}_{2}$ and $0.2 \mathrm{~mm}$ IPTG at room temperature. Immediately after the wash, the $E$. coli cells were treated with a chemical probe specific for unpaired DNA bases, CAA, at $37^{\circ} \mathrm{C}$ for 30 min. The plasmid DNAs were prepared by the alkaline-SDS lysis method (Maniatis et al. 1982) followed by $2 \times \mathrm{CsCl}$ density gradient centrifugation. CAA-reacted sites in the plasmid DNAs were analyzed by the method of Kohwi and Kohwi-Shigematsu (1988).

\section{Acknowledgments}

We thank Drs. V.A. Zakian and M.F. Hoekstra for critical review of this manuscript and invaluable suggestions, and Dr. T. Kohwi-Shigematsu for valuable discussions. We also thank our colleagues at La Jolla Cancer Research Foundation for careful reading of this manuscript. We thank Miss Minoree Kohwi for editing the manuscript and Mr. H. Tran and M. Iguchi for excellent technical assistance. This work was supported by grants from the National Institutes of Health (RO1CA51377) and by funds provided by the Cigarette and Tobacco Related Disease Research Program of the University California (1KT98) to Y.K.

The publication costs of this article were defrayed in part by payment of page charges. This article must therefore be hereby marked "advertisement" in accordance with 18 USC section 1734 solely to indicate this fact.

\section{References}

Albertini, A.M., M. Hofer, M.P. Calos, and J.H. Miller. 1982. On the formation of spontaneous deletions: The importance of short sequence homologies in the generation of large deletions. Cell 29: 319-328.

Blackwell, T.K., M.W. Moore, G.D. Yancopoulos, H. Suh, S. Lutzker, E. Selsing, and F.W. Alt. 1986. Recombination between immunoglobulin variable region gene segments is enhanced by transcription. Nature 324: 585-589.

Borowiec, J.A. and J.D. Gralla. 1987. All three elements of the lac ps promoter mediate its transcriptional response to DNA supercoiling. J. Mol. Biol. 195: 89-97.

Brill, S.J. and R. Sternglanz. 1988. Transcription-dependent DNA supercoiling in yeast DNA topoisomerase mutants. Cell 54: 403-411.
Chiba, M., H. Shimizu, A. Fujimoto, H. Nashimoto, and H. Ikeda. 1989. Common sites for recombination and cleavage mediated by bacteriophage T4 DNA topoisomerase in vitro. J. Biol. Chem. 264: 12785-12790.

Clark, A.J. and K.B. Low. 1988. Pathways and systems of homologous recombination in Escherichia coli. In The recombination of genetic material (ed. K.B. Low), pp. 155-215. Academic Press, New York.

Clark, D.J. and G. Felsenfeld. 1991. Formation of nucleosomes on positively supercoiled DNA. EMBO $J$. 10: 387-395.

- 1992. A nucleosome core is transferred out of the path of a transcribing polymerase. Cell 71: 11-22.

Dayn, A., S. Malkhosyan, and S.M. Mirkin. 1992. Transcriptionally driven cruciform formation in vivo. Nucleic Acids Res. 20: 5991-5997.

deBoer, H.A., L.J. Comstock, and M. Vasser. 1983. The tac promoter: A functional hybrid derived from the trp and lac promoters. Proc. Natl. Acad. Sci. 80: 21-25.

Droge, P. and A. Nordheim. 1991. Transcription-induced conformational change in a topologically closed DNA domain. Nucleic Acids Res. 19: 2941-2946.

Dul, J.L. and H. Drexler. 1988. Transcription stimulates recombination II. Generalized transduction of Escherichia coli by phages T1 and T4. Virology 162: 471-477.

Giaever, G.N. and J.C. Wang. 1988. Supercoiling of intracellular DNA can occur in eukaryotic cells. Cell 55: 849-856.

Goodman, S.D. and H.A. Nash. 1989. Functional replacement of a protein-induced bend in a DNA recombination site. $\mathrm{Na}$ ture 341: 251-254.

Howard-Flanders, P. and L. Theriot. 1966. Mutants of Escherichia coli K-12 defective in DNA repair and in genetic recombination. Genetics 53: 1137-1150.

Kohwi, Y. and T. Kohwi-Shigematsu. 1988. Magnesium iondependent triple-helix structure formed by homopurine-homopyrimidine sequences in supercoiled plasmid DNA. Proc. Natl. Acad. Sci. 85: 3781-3785.

- 1991. Altered gene expression correlates with DNA structure. Genes \& Dev. 5: 2547-2554.

Kohwi, Y., S.R. Malkhosyan, and T. Kohwi-Shigematsu. 1992. Intramolecular dG.dG.dC triplex detected in Escherichia coli cells. I. Mol. Biol. 223: 817-822.

Kohwi-Shigematsu, T. and Y. Kohwi. 1985. Poly(dG)-poly(dC) sequences, under torsional stress, induce an altered DNA conformation upon neighboring DNA sequences. Cell 43: 199-206.

- 1991. Detection of triple-helix related structures adopted by poly(dG)-poly(dC) sequences in supercoiled plasmid DNA. Nucleic Acids Res. 19: 4267-4271.

- 1992. Detection of non-B-DNA structures at specific sites in supercoiled plasmid DNA and chromatin with haloacetaldehyde and diethyl pyrocarbonate. Methods Enzymol. 212: $155-180$.

Kowalczykowski, S.C. 1991. Biochemistry of genetic recombination: Energetics and mechanism of DNA strand exchange. Annu. Rev. Biophys. Chem. 20: 539-575.

Landy, A. 1989. Dynamic, structural, and regulatory aspects of $\lambda$ site-specific recombination. Annu. Rev. Biochem. 58: 913949.

Lilley, D.M.J. and C.F. Higgins. 1991. Local DNA topology and gene expression: The case of the leu-500 promoter. Mol. Microbiol. 5: 779-783.

Liu, L.F. and J.C. Wang. 1987. Supercoiling of the DNA template during transcription. Proc. Natl. Acad. Sci. 84: 7024-7027.

Maniatis, T., E.F. Fritsch, and J. Sambrook. 1982. In Molecular cloning: A laboratory manual. Cold Spring Harbor Laboratory Press, Cold Spring Harbor, New York. 
Marvo, S.L., S.R. King, and R. Jaskunas. 1983. Role of short regions of homology in intermolecular illegitimate recombination events. Proc. Natl. Acad. Sci. 80: 2452-2456.

Maxam, A.W. and W. Gilbert. 1980. Sequencing end-labeled DNA with basic-specific chemical cleavage. Methods Enzymol. 65: 499-560.

Menzel, R., and M. Gellert. 1987. Modulation of transcription by DNA supercoiling: A deletion analysis of the Escherichia coli gyrA and gyrB promoters. Proc. Natl. Acad. Sci. 84: 4185-4189.

Moriya, M., M. Takeshita, F. Johnson, K. Peden, S. Will, and A.P. Grollman. 1988. Targeted mutations induced by a single acetylaminofluorene DNA adduct in mammalian cells and bacteria. Proc. Natl. Acad. Sci. 85: 1586-1589.

Nash, H.A. 1990. Bending and supercoiling of DNA at the attachment site of bacteriophage $\lambda$. Trends Biochem. Sci. 15: 222-227.

Panyutin, I.G. and R.D. Wells. 1992. Nodule DNA in the $(\mathrm{GA})_{37} \cdot(\mathrm{CT})_{37}$ insert in superhelical plasmids. $J$. Biol. Chem. 267: 5495-5501.

Petes, T.D. and C.W. Hill. 1988. Recombination between repeated genes in microorganisms. Annu. Rev. Genet. 22: $147-168$.

Radding, C.M. 1988. Homologous pairing and strand exchange promoted by Escherichia coli RecA protein. In Genetic recombination (ed. R. Kucherlapati and G.R. Smith), pp. 193229. American Society for Microbiology, Washington, D.C.

Rahmouni, A.R. and R.D. Wells. 1992. Direct evidence for the effect of transcription on local DNA supercoiling in vivo. $J$. Mol. Biol. 223: 131-144.

Smith, D.B. and K.S. Johnson. 1988. Single-step purification of polypeptides expressed in Escherichia coli as fusions with gultathione S-transferase. Gene 67: 31-40.

Smith, G.R. 1988. Homologous recombination in prokaryotes. Microbiol. Rev. 52: 1-28.

Southern, E.M. 1975. Detection of specific sequences among DNA fragments separated by gel electrophoresis. I. Mol. Biol. 98: 503-517.

Snyder, U.K., J.F. Thompson, and A. Landy. 1989. Phasing of protein-induced DNA bends in a recombination complex. Nature 341: 255-257.

Takahashi, K., M. Vigneron, H. Matthes, A. Wildeman, M. Zenke, and P. Chambon. 1986. Requirement of stereo specific alignments for initiation from the simian virus 40 early promoter. Nature 319: 121-126.

Thomas, B.J. and R. Rothstein. 1989a. The genetic control of direct-repeat recombination in Saccharomyces: The effect of rad52 and rad1 on mitotic recombination at GAL10, a transcriptionally regulated gene. Genetics 123: 725-738.

. 1989 b. Elevated recombination rates in transcriptionally active DNA. Cell 56: 619-630.

Tsao, Y-P., H-Y. Wu, and L.F. Liu. 1989. Transcription-driven supercoiling of DNA: Direct biochemical evidence from in vitro studies. Cell 56: 111-118.

Voelkel-Meiman, K., R.L. Keil, and G.S. Roeder. 1987. Recombination-stimulating sequences in yeast ribosomal DNA correspond to sequences regulating transcription by RNA polymerase I. Cell 48: 1071-1079.

Wu, H-Y., S. Shyy, J.C. Wang, and L.F. Liu. 1988. Transcription generates positively and negatively supercoiled domains in the template. Cell 53: 433-440.

Yancopoulos, G.D., T.K. Blackwell, H. Suh, L. Hood, and F.W. Alt. 1986. Introduced $T$ cell receptor variable region gene segments in pre-B cells: Evidence that $\mathrm{B}$ and $\mathrm{T}$ cells use a common recombinase. Cell 44: 251-259. 


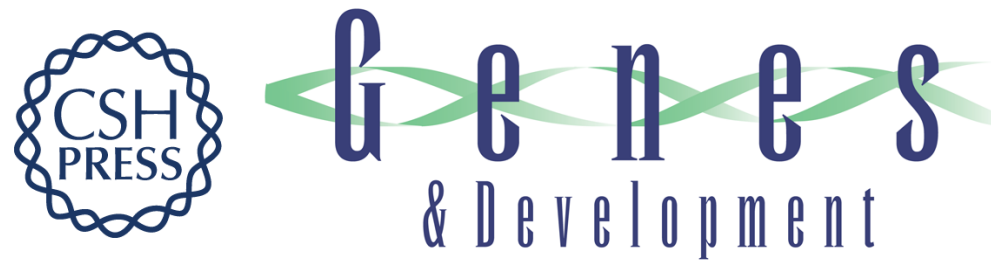

\section{Transcription-dependent recombination induced by triple-helix formation.}

Y Kohwi and Y Panchenko

Genes Dev. 1993, 7:

Access the most recent version at doi:10.1101/gad.7.9.1766

References This article cites 43 articles, 12 of which can be accessed free at:

http://genesdev.cshlp.org/content/7/9/1766.full.html\#ref-list-1

License

Email Alerting

Service

Receive free email alerts when new articles cite this article - sign up in the box at the top right corner of the article or click here.

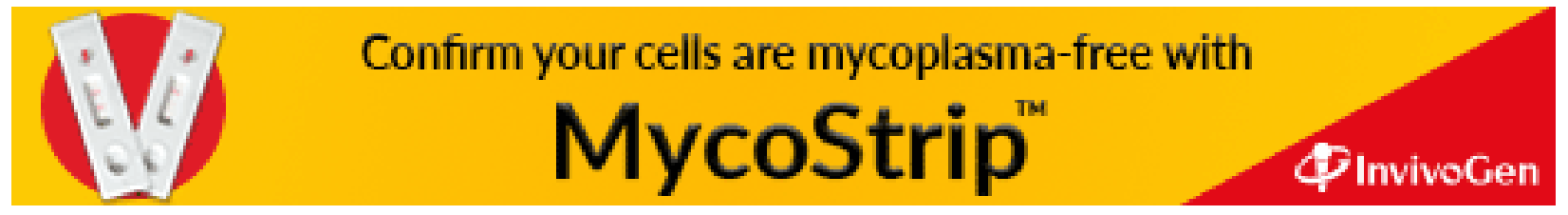

